\title{
ADVANCED PRESSURE BOUNDARY MATERIALS
}

\author{
Michael Santella \\ Oak Ridge National Laboratory, 1 Bethel Valley Road, Oak Ridge, TN 37931-6096 \\ Email: santellaml@ ornl.gov; Telephone: 865-574-4805 \\ John Shingledecker \\ Oak Ridge National Laboratory, 1 Bethel Valley Road, Oak Ridge, TN 37931-6155 \\ Email: shingledecip@ornl.gov; Telephone: 865-574-4929
}

\begin{abstract}
Increasing the operating temperatures of fossil power plants is fundamental to improving thermal efficiencies and reducing undesirable emissions such as $\mathrm{CO}_{2}$. One group of alloys with the potential to satisfy the conditions required of higher operating temperatures is the advanced ferritic steels such as ASTM Grade 91, 9Cr-2W, and 12Cr-2W. These are Cr-Mo steels containing 9-12 wt\% Cr that have martensitic microstructures. Research aimed at increasing the operating temperature limits of the $9-12 \mathrm{wt} \% \mathrm{Cr}$ steels and optimizing them for specific power plant applications has been actively pursued since the 1970's. As with all of the high strength martensitic steels, specifying upper temperature limits for tempering the alloys and heat treating weldments is a critical issue. To support this aspect of development, thermodynamic analysis was used to estimate how this critical temperature, the $A_{l}$ in steel terminology, varies with alloy composition. The results from the thermodynamic analysis were presented to the Strength of Weldments subgroup of the ASME Boiler \& Pressure Vessel Code and are being considered in establishing maximum postweld heat treatment temperatures. Experiments are also being planned to verify predictions. This is part of a CRADA project being done with Alstom Power, Inc.
\end{abstract}

\section{INTRODUCTION}

Postweld heat treatment (PWHT) is the process of annealing welds after welding operations are completed for the purpose of improving their properties or mitigating potential problems. ${ }^{1}$ It can produce both metallurgical and mechanical effects that depend on the chemical composition of the alloy being treated, its processing history prior to and including welding, and the specific details of the PWHT including heating and cooling rates, annealing temperatures, and holding times. ${ }^{1-3}$ For carbon and alloy steels, PWHT may be used for a variety of reasons including reducing or redistributing residual stresses, controlling distortion in subsequent fabrication operations, tempering hardened microstructures, restoring toughness, removing hydrogen, and minimizing stress corrosion cracking. ${ }^{2,3}$

Temperature control in PWHT is critical from both a metallurgical and a practical perspective. Metallurgically, maximum temperatures will largely govern the kinetics of annealing phenomena and the thermodynamic stability of microstructures. ${ }^{4-6}$ In practice, it is generally desirable to use the highest PWHT temperature possible to minimize processing time, labor, and energy resources. Of course, temperature control is a key element of all heat treating operations so knowing important transformation temperatures and how microstructures vary with temperature is critical for effective processing. For convenience when heat treating carbon and alloy steels, critical temperatures and temperature ranges are customarily based on terms associated with the iron-carbon binary phase diagram. For example, under equilibrium condi- 
tions, the lowest temperature where the austenite phase is stable is designated as $A_{l}$, and the lowest temperature where a hypo-eutectoid steel (C concentration $<\sim 0.8 \mathrm{wt} \%$ ) is $100 \%$ austenite is referred to $A_{3}{ }^{1}$

Of the various transformation temperatures associated with the $\mathrm{Fe}-\mathrm{C}$ binary system, the most important one for PWHT of carbon and alloy steel weldments is $A_{l}$. One of the more common features of weldments in these steels is the formation of hard microstructures, typically martensite, in either the weld deposits, the heat affected zones of the base metal, or both. Postweld heat treatment is then used to temper the microstructure with the intent of restoring some toughness. ${ }^{2,3}$ Implicit expectations of PWHT are that all existing martensite is tempered and no new martensite is formed. The only way new, untempered martensite can form during PWHT is by exceeding the $A_{l}$. This condition would cause austenite to form. The austenite could then transform to untempered martensite during cooling depending on the chemical composition of the steel in question and the details of its transformation behavior.

The Cr-Mo steels containing 9-12\% $\mathrm{Cr}$ are among the highest strength ferritic alloys that are suitable for construction of large power generation components such as piping and manifolds for boilers and heat exchangers, turbine parts, and pressure vessels that operate at elevated temperatures. ${ }^{7}$ These are martensitic alloys that generally contain strengthening precipitates of $\mathrm{M}_{23} \mathrm{C}_{6}$, various $\mathrm{M}(\mathrm{C}, \mathrm{N})$ phases, and possibly intermetallic phases. They are typically used in a heat treated condition referred to as normalized and tempered. They are frequently welded, and PWHT is almost always required for components built to ASME Boiler \& Pressure Vessel Code requirements. ${ }^{8}$

An important item in the ASME Code rules is specification of PWHT requirements. When it is required, welds in the $9-12 \% \mathrm{Cr}$ steels must be postweld heat treated at a minimum of $704^{\circ} \mathrm{C}$. The rules for construction of power boilers and pressure vessels also specify that maximum temperatures exceeding the $704^{\circ} \mathrm{C}$ minimum are permissible. ${ }^{8}$ However, the intention of the ASME Code requirements is that higher PWHT temperatures, if used, do not exceed the $A_{l}$ of the alloy being heat treated. It is recognized that there are limited data from experimental measurements of $A_{l}$ 's, and that the base metal specifications for both 9 and $12 \mathrm{Cr}$ steels span ranges that may result in large variations of $A_{l}$ 's. Because of these uncertainties, this study was undertaken to evaluate the variations of $A_{l}$ 's in several of these steels using commercially available (Thermo-Calc) computational thermodynamics analysis. This information would then be factored into possible future limitations on maximum permissible PWHT temperatures for the 9-12 $\mathrm{Cr}$ steels. Also, some data are presented to illustrate the effect of heating rate on the measured $A_{l}$ of a $9 \mathrm{Cr}$ steel using a high temperature extensometer on a Gleeble ${ }^{\circledR}$ machine.

\section{EXPERIMENTAL}

The steel compositions subjected to thermodynamic analysis for estimation of the variations of $A_{I}$ 's are shown in Table 1. The composition ranges specified in ASTM A387 for product analysis were used for those of Grade 91 and Grade 911. The composition ranges of the $9 \mathrm{Cr}-2 \mathrm{~W}$ and the $12 \mathrm{Cr}-2 \mathrm{~W}$ alloys were taken respectively from Case 2179-3 and Case 2180-2 of the ASME Boiler and Pressure Vessel Code. The composition range for the SAVE12 alloy was taken from Sumitomo product certification information. The minor elements $\mathrm{Al}, \mathrm{B}, \mathrm{P}$ and $\mathrm{S}$ were ignored in the analyses because their effects on the $A_{l}$ 's was expected to be slight. The elements $\mathrm{Nd}$ and Hf were also omitted from the SAVE12 composition ${ }^{9}$ because they are not treated in the available thermochemical databases for steels, but their effects on $A_{l}$ 's are also expected to be very small.

The analyses for estimating the variations of $A_{l}$ with composition were done using Thermo-Calc software with the Fe-DATA version 6 thermochemical database. ${ }^{10}$ To produce groups of alloys that spanned 
Table 1. Alloy composition ranges

\begin{tabular}{lccccc}
\hline & \multicolumn{5}{c}{ Composition range, wt\% } \\
\hline Element & Grade 91 & Grade 911 & 9Cr-2W & SAVE12 & 12Cr-2W \\
\hline Carbon & $0.06-0.15$ & $0.08-0.14$ & $0.07-0.13$ & $0.08-0.13$ & $0.07-0.14$ \\
Manganese & $0.25-0.66$ & $0.25-0.66$ & $0.30-0.60$ & $0.10-0.80$ & 0.70 \\
Silicon & $0.18-0.56$ & $0.08-0.56$ & 0.50 & 0.50 & 0.50 \\
Chromium & $7.90-9.60$ & $8.40-10.70$ & $8.50-9.50$ & $8.80-12.00$ & $10.00-12.50$ \\
Molybdenum & $0.80-1.10$ & $0.85-1.15$ & $0.30-0.60$ & --- & $0.25-0.60$ \\
Tungsten & --- & $0.85-1.15$ & $1.50-2.00$ & $2.50-3.50$ & $1.50-2.50$ \\
Nickel & 0.43 & 0.43 & 0.40 & --- & 0.50 \\
Cobalt & --- & --- & --- & $2.50-6.00$ & --- \\
Copper & --- & --- & --- & --- & $0.30-1.70$ \\
Vanadium & $0.16-0.27$ & $0.16-0.27$ & $0.15-0.25$ & $0.20-0.40$ & $0.15-0.30$ \\
Niobium & $0.05-0.11$ & $0.05-0.11$ & $0.04-0.09$ & $0.20-0.10$ & $0.04-0.10$ \\
Tantalum & --- & --- & --- & 0.20 & --- \\
Nitrogen & $0.025-0.080$ & $0.035-0.095$ & $0.030-0.070$ & 0.050 & $0.040-0.100$ \\
& & & & & 1305 \\
\hline Conditions & 1812 & 2012 & 2004 & 1740 \\
\hline
\end{tabular}

each specification range, five reference compositions were selected for each alloy. Then each element was varied from its minimum to its maximum while all other elements were maintained at their reference values. The 5 reference compositions were:

1. Each element set to the mid-point of its specified range

2. Austenite stabilizers ${ }^{5}(\mathrm{C}, \mathrm{Co}, \mathrm{Cu}, \mathrm{Mn}, \mathrm{Ni}, \mathrm{N})$ set to their specified maximums; ferrite stabilizers ${ }^{5}$ (Cr, Mo, Nb, Si, Ta, V, W) set to their specified minimums

3. Ferrite stabilizers set to their specified maximums; austenite stabilizers set to their specified minimums

4. Each element set to the maximum specified for its range

5. Each element set to the minimum specified for its range

Default conditions in Thermo-Calc divided each individual composition range into 40 equally spaced intervals. While this approach did not produce totally random sets of chemical compositions, it did encompass the upper and lower chemistry limits of each alloy. The total number of unique chemical compositions generated by this approach for each alloy specification are indicated as Conditions in Table 1. The basic procedure for calculating the $A_{l}$ 's involved verifying that temperature was within the lower austenite + ferrite phase field, and then releasing constraints on temperature and calculating the equilibrium conditions where the austenite phase disappeared. The phases included in the equilibrium calculations were austenite (fcc iron), ferrite (bcc iron), $\mathrm{M}_{6} \mathrm{C}, \mathrm{M}_{23} \mathrm{C}_{6}, \mathrm{M}(\mathrm{C}, \mathrm{N})$, sigma phase, and laves phase. For the $12 \mathrm{Cr}-2 \mathrm{~W}$ steel the possibility of $\mathrm{Cu}$ phase formation was also considered in the analysis.

A specimen of SAVE12 alloy was used to evaluate the effect of heating rate on measured $A_{l}$. The analyzed chemical composition of this specimen was Fe-0.099C-0.68Mn-0.25Si-9.89Cr-3.08W-3.21Co$0.31 \mathrm{Ni}-0.05 \mathrm{Nb}-0.31 \mathrm{~V}-0.013 \mathrm{~N}$, wt $\%$. A Gleeble ${ }^{\circledR}$ machine was used for the experiments which were conducted in vacuum by heating a $10-\mathrm{mm}$-diameter rod to $1100^{\circ} \mathrm{C}$ at rates of $2,20,200$, and $2000^{\circ} \mathrm{C} / \mathrm{min}$. A single specimen was used for all the measurements which were done in the order of highest to lowest heating rate. The rod was given a solution treatment of $1100^{\circ} \mathrm{C}$ for $15 \mathrm{~min}$ prior to the heating rate experiments. A high temperature diametral extensometer (Model 3580, Epsilon Technology Corp.) was 
used to record instantaneous changes of specimen diameter during the heating/cooling cycles. The extensometer was attached to the specimen rod at the position of a thermocouple that was used for closed-loop feedback control of temperature. This is a fairly common arrangement for Gleeble ${ }^{\circledR}$ experiments.

\section{RESULTS}

The predictions for ranges of $A_{l}$ 's for the $9 \mathrm{Cr}$ steels are shown in Figure 1 and for the $12 \mathrm{Cr}-2 \mathrm{~W}$ steel in Figure 2. The results were plotted as histograms mainly to enable a graphical display, but the histograms show some noteworthy features. Each histogram in Figure 1 contains 5 prominent peaks that are centered on the 5 reference chemical compositions. The peaks at the low temperature extrema correspond to the reference no. 2 compositions in each alloy where the austenite formers were maximized and the ferrite formers were minimized. The order of the peaks from lowest to highest predicted $A_{l}$ 's was reference nos. $2,4,1,5$, and 3 . One reason the peaks at each reference composition are so prominent relates to the choice of accepting default conditions for varying individual elements within their specified ranges. For example, elements such as the carbide formers $\mathrm{Nb}$, Ta, and $\mathrm{V}$ occur in relatively small composition ranges and they have relatively small effects on $A_{l}$. This is the main reason there are relatively large frequencies of compositions centered about the 5 reference conditions.

Figure 1 shows that the minimum predicted $A_{l}$ 's increased with the sophistication of the alloying used to maximize creep strengths. ${ }^{7}$ It is likely that the expanded ranges of $A_{l}$ 's for Grade 911 and SAVE12 are the result of having larger specified ranges for $\mathrm{Cr}$ additions compared to Grade 91 and $9 \mathrm{Cr}-2 \mathrm{~W}$.

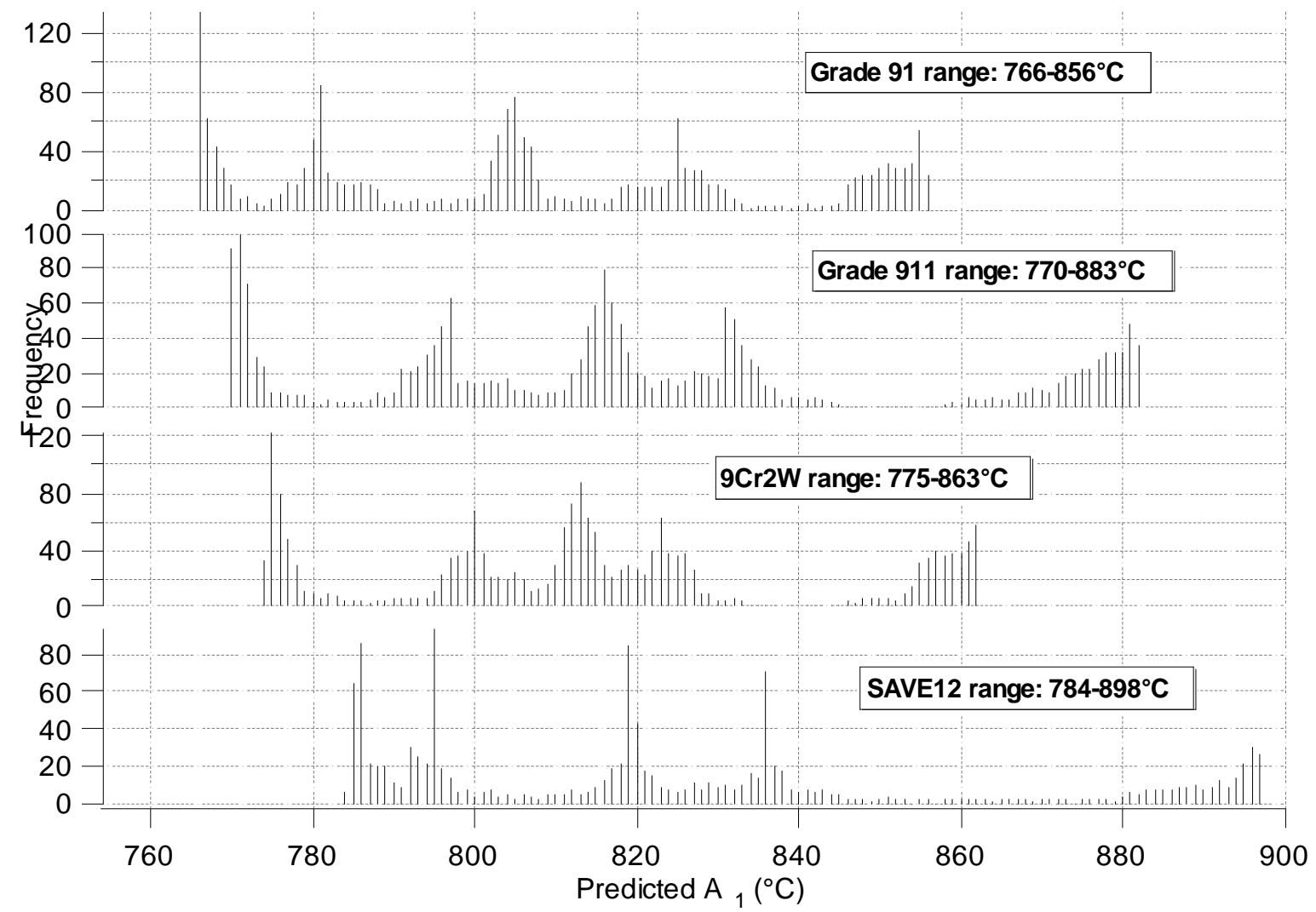

Figure 1. Histogram frequency plots of predicted $A_{l}$ 's for $9 \mathrm{Cr}$ steels. 
There are only 4 major peaks for the $12 \mathrm{Cr}-2 \mathrm{~W}$ steel predictions shown in Figure 2 because the analysis of this alloy is incomplete. The only condition not yet done is reference composition no. 5 that has all elements set to their minimum specified ranges. However, the extrema conditions of reference composition nos. 2 and 3 are shown so the predicted $A_{l}$ range for this alloy is accurately represented in Figure 2.

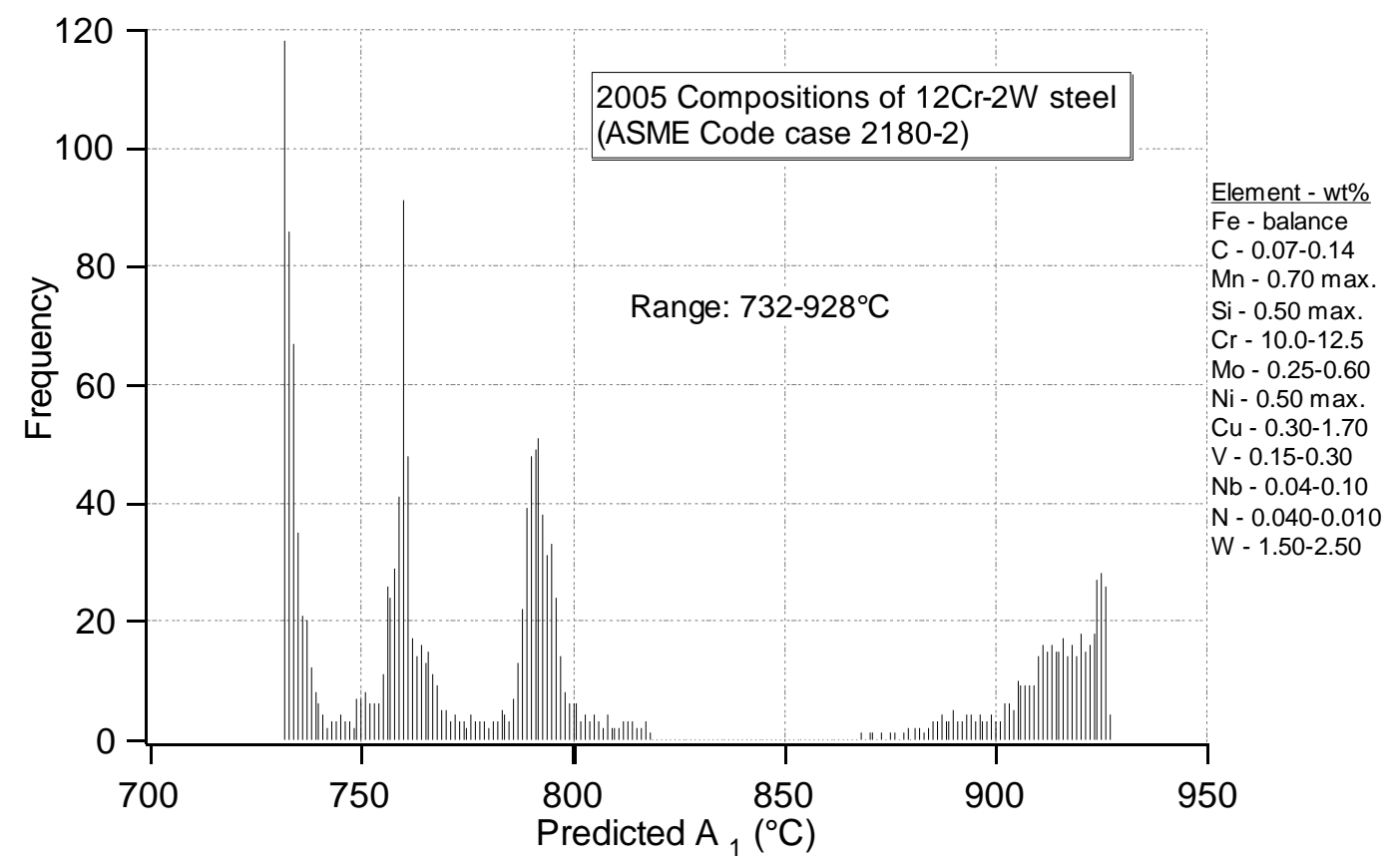

Figure 2. Histogram frequency plot of predicted $A_{l}$ for $12 \mathrm{Cr}-2 \mathrm{~W}$ steel.

The results from measurements of the effects of heating rate on the details of austenite formation and growth in the SAVE12 alloy are presented in Figure 3. Austenite fractions were determined from thermal arrests that occurred during heating using the procedure described by Eldis. ${ }^{11}$ The measurements show that the detected start temperature for austenite formation systematically increased with heating rate. Experimentally measured austenite transformation start temperatures are designated by $A_{C I}$ to distinguish them from true equilibrium temperatures, $A_{l} .{ }^{1}$ Figure 3 shows that increasing the heating rate from $2^{\circ} \mathrm{C} / \mathrm{min}$ to $2000^{\circ} \mathrm{C} / \mathrm{min}$ increased $A_{C l}$ about $70^{\circ} \mathrm{C}$. At the $2^{\circ} \mathrm{C} / \mathrm{min}$ heating rate austenite formation was detected around $810^{\circ} \mathrm{C}$, about $35^{\circ} \mathrm{C}$ higher than the $A_{l}$ predicted by equilibrium thermodynamics.

\section{DISCUSSION}

Except for SAVE 12, the other four steels analyzed conform to the material designation of P5B Group 2 that is used by the ASME Code to classify materials for PWHT requirements. ${ }^{8}$ In other words, according to ASME Code requirements Grade 91 , Grade $911,9 \mathrm{Cr}-2 \mathrm{~W}$ steel, and $12 \mathrm{Cr}-2 \mathrm{~W}$ steel must all be postweld heat treated using the same rules. These rules require a minimum PWHT temperature of $704^{\circ} \mathrm{C}$ with higher temperatures permitted but not specified. If one rule was used to limit the PWHT temperature for the steels then the results presented in Figures $1 \& 2$ indicate that the maximum limiting temperature should be $732^{\circ} \mathrm{C}$. This is the lowest predicted temperature where austenite is stable in the $12 \mathrm{Cr}-2 \mathrm{~W}$ steel. Limiting PWHT of the P5B Group 2 steels to less than $732^{\circ} \mathrm{C}$ should prevent the formation of unwanted austenite and subsequent untempered martensite in all of these alloys including SAVE12. The SAVE12 


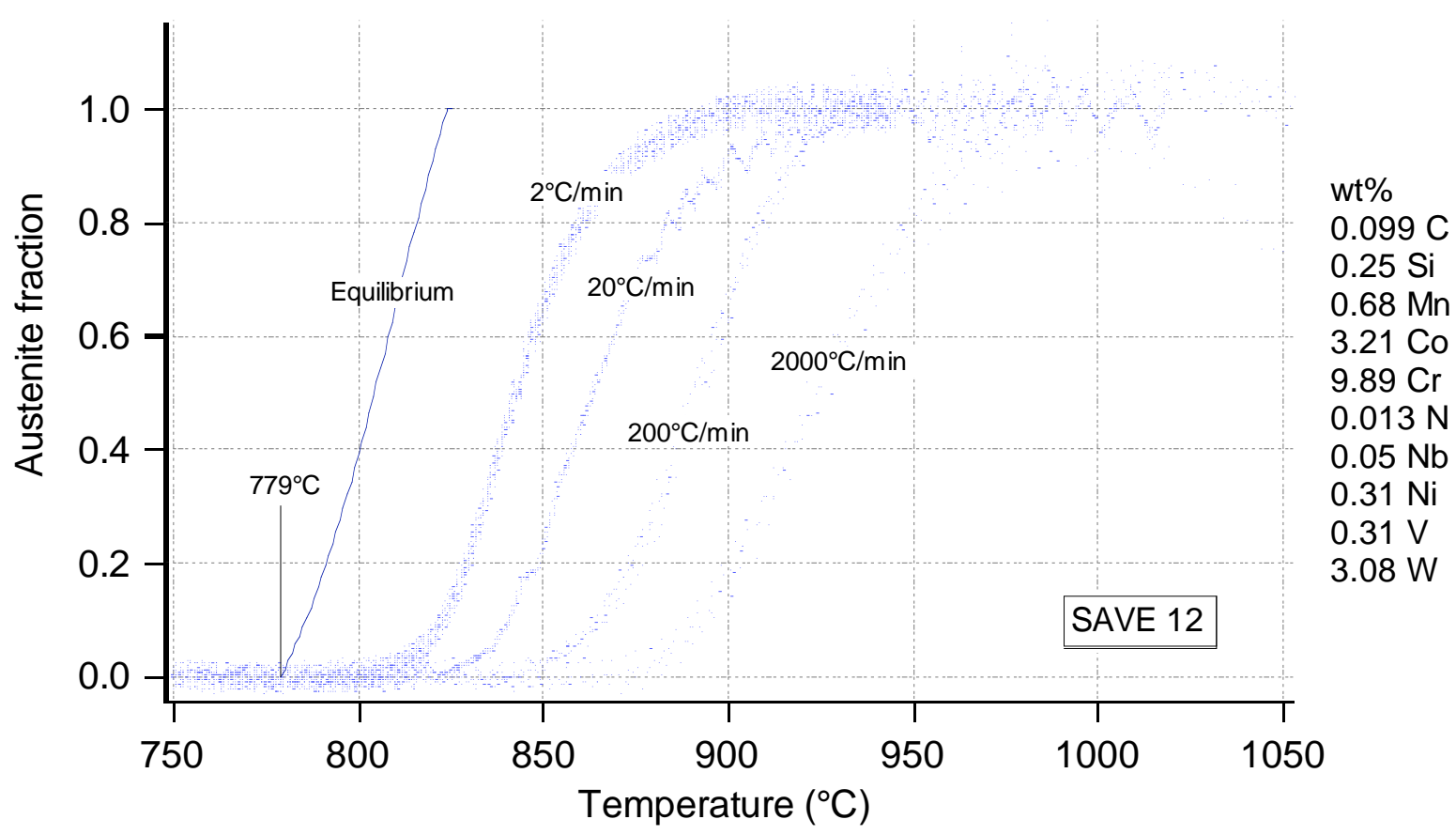

Figure 3. Variation with temperature of measured austenite fraction in SAVE12 alloy for 4 heating rates. The variation of the equilibrium austenite amount was calculated.

steel is not approved for ASME Code constructions but judging by the similarity of its chemical composition to those of the P5B Group 2 alloys it would likely be assigned to this designation if it were approved.

This study also suggests information derived from computational thermodynamics analysis could be a reasonable alternative to specifying PWHT temperature limits rather than by rules that cover wide ranges of alloy behavior. Of course, this would require access to the computational thermodynamics tools like Thermo-Calc and the appropriate databases. In addition, it would also be prudent to supplement thermodynamic information with some experimental measurements of $A_{l}$ to build confidence in the accuracy of the predictions.

The data presented in Figure 3 graphically illustrate the effects heating rate has on measuring the starting temperature and progress of austenite formation. The increase with heat rate of $A_{C l}$ relative to $A_{l}$ is basically due to austenite formation occurring by diffusion controlled nucleation and growth. Nucleation events typically involve an initial incubation period. Subsequent growth of newly formed austenite grains will occur by diffusional processes. Consequently, increases in heating rate reduce the time available for formation at the equilibrium temperature and they produce the appearance of higher than equilibrium transformation temperatures. The calculated $A_{1}$ is about $35^{\circ} \mathrm{C}$ below the $A_{C l}$ measured at $2^{\circ} \mathrm{C} / \mathrm{min}$ heating. This is a very slow heating rate, about as slow as is practical for the Gleeble ${ }^{\circledR}$, suggesting that ThermoCalc may be underestimating $A_{l}$ in the SAVE12 alloy system. 


\section{CONCLUSION}

Analysis by computational thermodynamics was used to predict the temperature range and the absolute minimum equilibrium temperature, i.e., $A_{l}$, where austenite is stable for the specified composition range for each of $5 \mathrm{Cr}$-Mo steels. The steels and the predicted values are:

$$
\begin{aligned}
& \text { A387 Grade } 91, \text { minimum } A_{l}=766^{\circ} \mathrm{C}, A_{l} \text { range }=766-856^{\circ} \mathrm{C} \\
& \text { A387 Grade } 911, \text { minimum } A_{l}=770^{\circ} \mathrm{C}, A_{l} \text { range }=770-883^{\circ} \mathrm{C} \\
& \text { 9Cr-2W, minimum } A_{l}=775^{\circ} \mathrm{C}, A_{l} \text { range }=775-863^{\circ} \mathrm{C} \\
& 12 \mathrm{Cr}-2 \mathrm{~W}, \text { minimum } A_{l}=732^{\circ} \mathrm{C}, A_{l} \text { range }=732-928^{\circ} \mathrm{C} \\
& \text { SAVE12, minimum } A_{l}=784^{\circ} \mathrm{C}, A_{l} \text { range }=784-898^{\circ} \mathrm{C}
\end{aligned}
$$

Measurements showed that the start of austenite transformation, $A_{C l}$, of SAVE12 increased from about $810^{\circ} \mathrm{C}$ for heating at $2^{\circ} \mathrm{C} / \mathrm{min}$ to about $880^{\circ} \mathrm{C}$ for heating at $2000^{\circ} \mathrm{C} / \mathrm{min}$. Equilibrium calculation, representing infinitely slow heating rate, estimated a transformation temperature of $A_{l}=779^{\circ} \mathrm{C}$.

\section{ACKNOWLEDGEMENT}

The support and encouragement of certain colleagues cannot be overstated. These include Jeff Henry of Alstom Power, Inc., Bob Swindeman retired from the Oak Ridge National Laboratory, and the members of the ASME Boiler \& Pressure Vessel Committee Subgroup on Strength of Weldments.

\section{REFERENCES}

1. ASM Handbook, Volume 4, Heat Treating (online), Third Printing (1995), ASM International

2. R. D. Stout, "Postweld Heat Treatment of Pressure Vessels," Welding Research Council Bulletin 302, February, 1985, pp. 1-14

3. C. E. Spaeder, Jr. and W. D. Doty, “ASME Post-weld Heat Treating Practices: An Interpretive Report," Welding Research Council Bulletin 407, December, 1995, pp. 50-65

4. Steels: Microstructures and properties, Second edition, R. W. K. Honeycombe and H. K. D. H. Bhadeshia, 1995, Edward Arnold, London

5. Phase Transformations in Metals and Alloys, Second edition, D. A. Porter and K. E. Easterling, 2001 reprint, Nelson Thornes Ltd, Cheltenham, United Kingdom

6. Transformations in Metals, P. G. Shewmon, 1969, McGraw-Hill, New York

7. R. L. Klueh, "Elevated temperature ferritic and martensitic steels and their application to future nuclear reactors," International Materials Reviews, vol. 50 (5), 2005, pp. 287-310

8. ASME Boiler and Pressure Vessel Code, "Rules for Construction of Power Boilers," Section I; "Rules for Construction of Nuclear Facility Components," Section III; and, "Rules for Construction of Pressure Vessels," Section VIII, The American Society of Mechanical Engineers, New York

9. M. Igarashi and Y. Sawaragi, "Development of 0.1C-11Cr-3W-3Co-V-Nb-Ta-Nd-N Ferritic Steel for USC Boilers, pp. 107-112 in Proceedings of International Conference on Power Engineering-97, Volume 2, The American Society of Mechanical Engineers, New York

10. N. Saunders, "Fe-DATA, a database for thermodynamic calculations for Fe alloys,"

Thermotech Ltd., Surrey Technology Centre, The Surrey Research Park,

Guilford, Surrey GU2 7YG, U.K.

11. G. T. Eldis, "A Critical Review of Data Sources for Isothermal and Continuous Cooling Transformation Diagrams," pp. 126-148 in Hardenability Concepts with Applications to Steels, The Metallurgical Society of AIME, Warrendale, Pennsylvania, 1978 